GEOAMBIENTE ON-LINE

Revista Eletrônica do Curso de Geografia do Campus Jataí - UFG www.jatai.ufg.br/geografia

| J ataí-GO | N.9 | jul-dez/2007

¿GEO

AMBIENTE

ISSN 1679-9860

\title{
GESTÃO AMBIENTAL EM UMA PROPRIEDADE RURAL NO MUNICÍPIO DE ITUPORANGA NO ALTO VALE DO ITAJAI - SC ${ }^{1}$
}

Cláudia Fernanda Willemann², Valter Antonio Becegato ${ }^{3}$, Olívia Aparecida Rodolfo Figueiredo $^{3}$, William César Pollonio Machado ${ }^{4}$

(1-Extraído da monografia da primeira autora do curso de Especialização em Meio Ambiente e Gestão Ambiental da UDESC/CAV; 2-Bióloga; claudyafw@yahoo.com.br; 3-Professor do Centro de Ciências Agroveterinárias da Universidade do Estado de Santa Catarina-UDESC. Caixa Postal 281, CEP 88520-000 Lages-SC, E-mail: becegato@cav.udesc.br; a2oaf@cav.udesc.br; 4-Professor da Universidade Federal Tecnológica do Paraná-UFTPRPato Branco-PR/IAP, E-mail: wcpm@mail.crea-pr.org.br.).

1

\section{Resumo}

Objetivou-se fazer um diagnostico de uma propriedade agrícola visando à implantação de um plano de gestão ambiental. Foi conduzido um trabalho na localidade de Cerro Negro município de Ituporanga estado de Santa Catarina. Elaborou-se um mapa da área com o auxilio de GPS (Sistema Posicionado por Satélite). Tomou-se medidas da largura dos rios e da mata ciliar correspondente. Foram feitas observações e entrevista com o proprietário para avaliar os diferentes tipos de atividades desenvolvidas na área. A propriedade possui 32 hectares sendo: 14 ha destinados para agricultura, 9 ha com pastagem e 9 ha com vegetação nativa. A área possui dois rios e algumas nascentes. O Rio Itajaí do Sul tem largura aproximada de 70 metros e caracteriza-se por possuir mata ciliar com largura entre 0 a 50 metros. O rio Indaiá afluente do anterior possui largura de 2,5 a 4 metros e possui apenas 10\% da mata ciliar necessário. De acordo com a legislação ambiental brasileira seriam necessários a implantação de aproximadamente 10 hectares de vegetação ciliar, o que inviabilizaria principalmente a produção de leite, uma das principais fontes de renda da propriedade. Observou-se que a propriedade necessita de maiores áreas de preservação permanente.

Palavras-chave: Gestão ambiental, legislação ambiental, uso e ocupação do solo

\section{Abstract \\ ENVIRONMENTAL MANAGEMENT IN A FARM IN THE MUNICIPALITY OF ITUPORANGA IN ALTO VALE DO ITAJAÍ - SC}

Recebida para publicação em 15 de Junho de 2007;

Aprovada para publicação em 01 de Outubro de 2007 


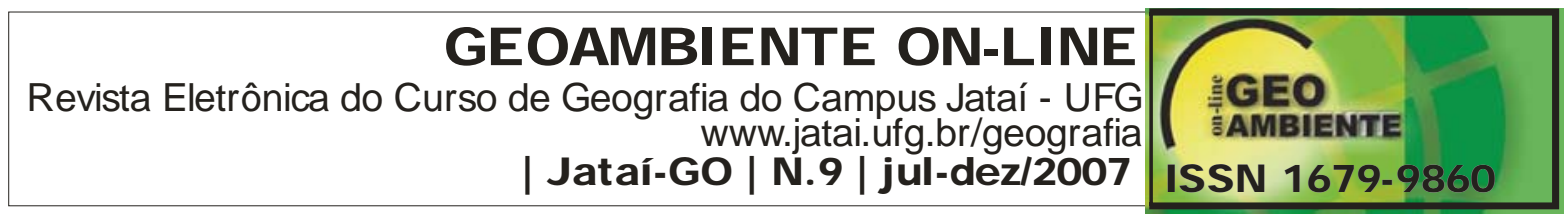

The project had as objective to diagnosis in a farm aiming at to the implantation of a plan of environmental management. City of Ituporanga in the state of Santa Catarina was lead a work in the locality of Black Cerro. A Map of the area was elaborated with device GPS (Global Positioning System). One was overcome measured by the width of the rivers and corresponding forest. Comments and interview with the proprietor had been made to evaluate the different types of use of the area. The property to have 32 ha being: 14 ha destined for agriculture, 9 ha with pasture and 9 ha with native forest. The area it has two rivers and some springs. The river Itajaí do Sul has approach width of 70 meters and is characterized for it has margin forest width interval the 0 up to 50 meters. The river affluent Indaiá of the previous one possess width of 2.5 the 4 meters and it has only $10 \%$ of the necessary margin forest. In accordance with the Brazilian environmental legislation the implantation of approximately 10 ha of margin forest, what it would make impracticable the milk production mainly, one of the main sources of income of the farm would be necessary. It was observed that the property needs bigger areas of permanent preservation.

Key-words: Environmental management, environmental legislation, use and occupation of the land

\section{1 - Introdução}

Ao iniciar-se um trabalho na área ambiental, encontram-se vários problemas, pois o meio é bastante complexo, principalmente quando visualizado no todo com os aspectos ambientais, sociais, econômicas, culturais e suas relações (ALMEIDA et al. 2000).

De acordo com cientistas das mais diversas regiões do planeta, está cada vez mais evidente, que as catástrofes ambientais que vêm ocorrendo, estão diretamente relacionados a mecanismo da busca do equilíbrio planetário (EHRLICH, 2000).

A terra está reagindo às diversas intervenções humanas como a superpopulação, o crescimento desordenado das indústrias e das cidades, o aumento desordenado da frota de carros, assim como no desmatamento de grandes áreas pela indústria madeireira e pela exploração agrícola.

Desde meados do século XIX quando iniciou a revolução industrial, o objetivo dos países principalmente os mais desenvolvidos foi de crescimento a qualquer custo. $\mathrm{O}$ pensamento até bem pouco tempo foi de que os recursos naturais eram infinitos; quando na verdade não o são. Os problemas enfrentados com a falta de água potável nos mais diversos 


\begin{tabular}{|c|c|}
\hline $\begin{array}{r}\text { GE OAMBIENTE ON-LINE } \\
\text { Revista Eletrônica do Curso de Geografia do Campus Jataí - UFG } \\
\text { www.jatai.ufg.br/geografia } \\
\text { | J ataí-GO | N.9 | jul-dez/2007 }\end{array}$ & $\begin{array}{l}\text { OCEO } \\
\text { ISSN } 1679-9860\end{array}$ \\
\hline
\end{tabular}

lugares do planeta, inseriram interrogações quanto a nossa fragilidade em relação ao planeta (LEGGET, 1992).

Nas empresas houve mudança de atitude com relação ao meio ambiente. Certificados de qualidade ambiental foram criados para diferenciar empresas que se preocupam com o meio ambiente, um exemplo é a ISO 14000. Já foi comprovado que empresas que trabalharam de acordo com normas e legislações ambientais tiveram maiores lucros e maior satisfação dos próprios empregados. Entende-se por gestão ambiental o processo seja de uma indústria, empresa ou empreendimento agrícola que sigam as normas da legislação (ALMEIDA et al. 2000).

Diante das características da propriedade, objetivou-se fazer um diagnóstico da mesma, dando ênfase a áreas de preservação permanente e o uso e ocupação do solo, fazendose um comparativo com as normas da legislação ambiental brasileira, cujo estudo servirá para aplicação de um plano de gerenciamento ambiental, considerando-se a sustentabilidade da propriedade.

\section{2 - Material e Métodos}

A área de estudo está localizada no Bairro Cerro Negro município de Ituporanga (Figura 1), no estado de Santa Catarina entre as coordenadas - Latitude S $27^{\circ} 28^{\prime} 44^{\prime \prime}$ e Longitude W $049^{\circ} 34^{\prime} 59.9^{\prime \prime}$

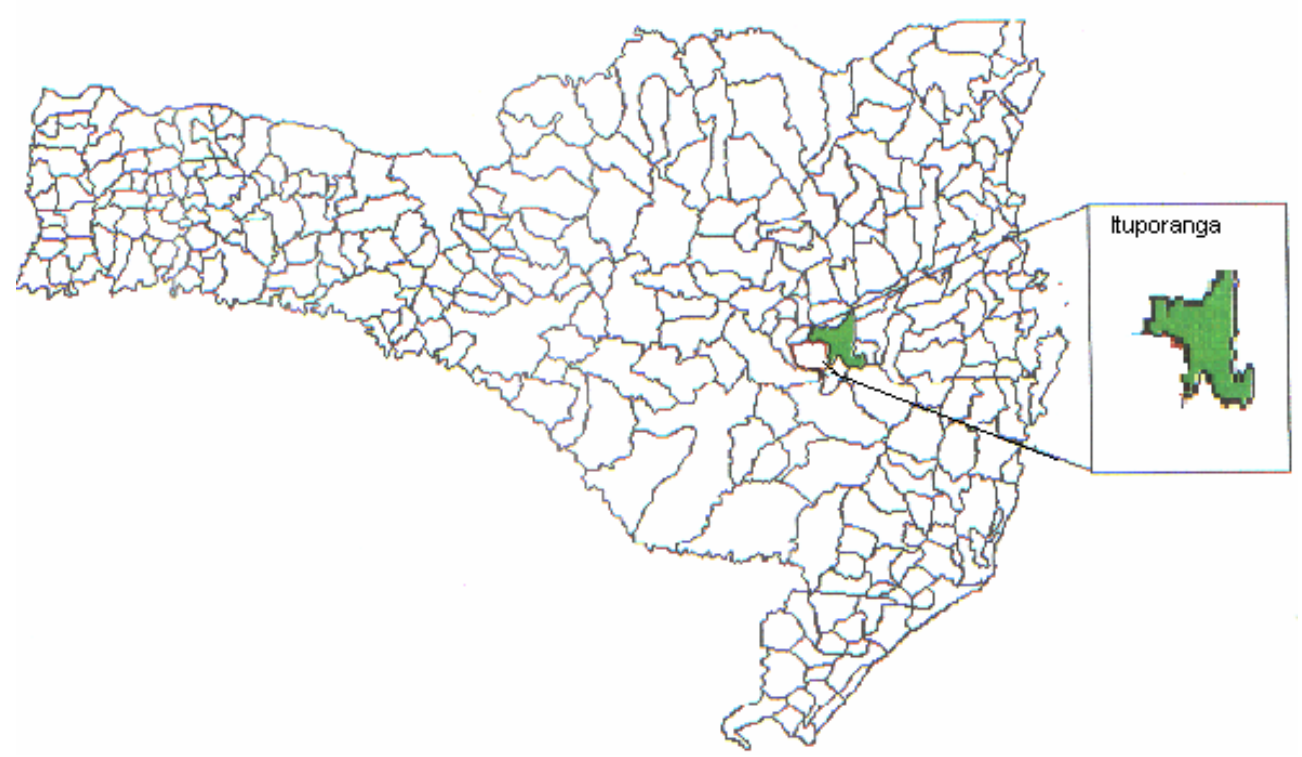

Figura 1 - Mapa de Santa Catarina e sua divisão política. 


\begin{tabular}{|c|c|}
\hline $\begin{array}{r}\text { GEOAMBIENTE ON-LINE } \\
\text { Revista Eletrônica do Curso de Geografia do Campus Jataí - UFG } \\
\text { www.jatai.ufg.br/geografia } \\
\text { || ataí-GO | N.9|jul-dez/2007 }\end{array}$ & $\begin{array}{l}\text { MEEO } \\
\text { ISTAMIENTE } \\
\text { ISSN } 1679-9860\end{array}$ \\
\hline
\end{tabular}

A propriedade possui 32 hectare (Figura 2), com clima mesotérmico úmido, verão quente e temperatura média de $17^{\circ} \mathrm{C}$, altitude de $390 \mathrm{~m}$ acima do nível do mar.

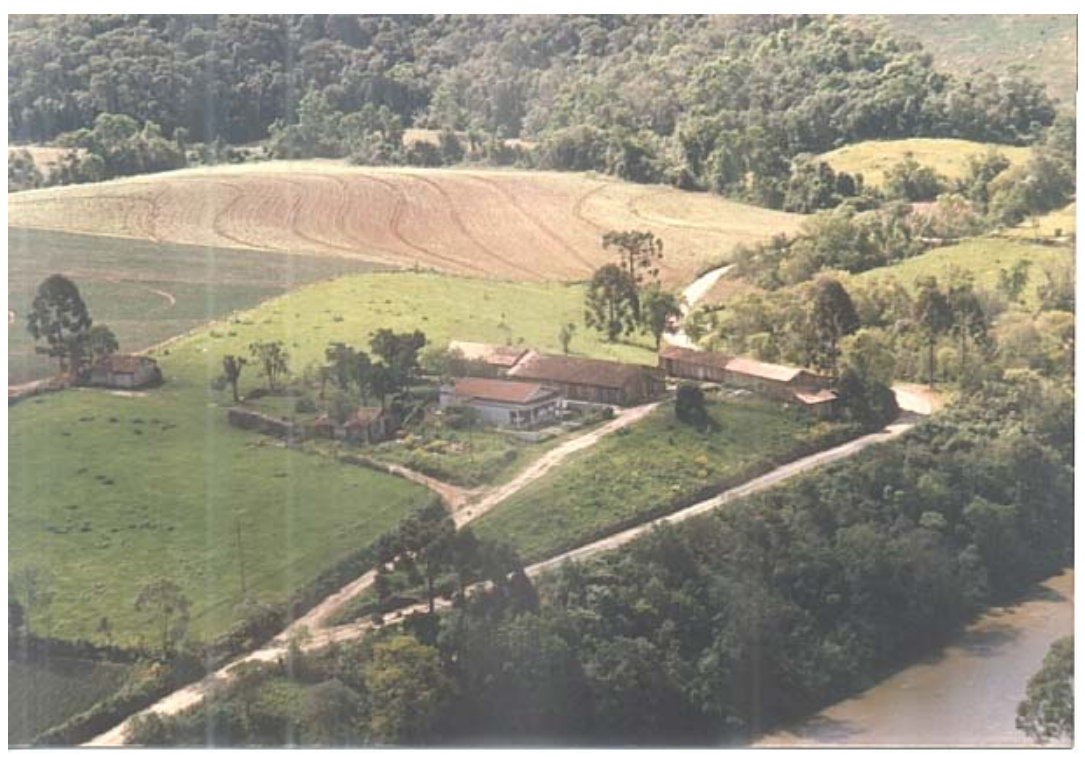

Figura 2 - Vista aérea da propriedade.

Elaborou-se um mapa georreferenciado da propriedade (Figura 3) com aparelho posicionado por satélite (GPS). Para demarcar a área caminhou-se pela divisa do terreno marcando os principais pontos (cantos do terreno). Estes foram lançados em programa de computador, objetivando traçar o polígono da área. A mata ciliar foi medida com trena, observando os principais rios e nascentes. A projeção da mata ciliar adequada foi feita baseada na legislação ambiental brasileira, Código Florestal Lei nº 4.771 (BRASIL, 1965).

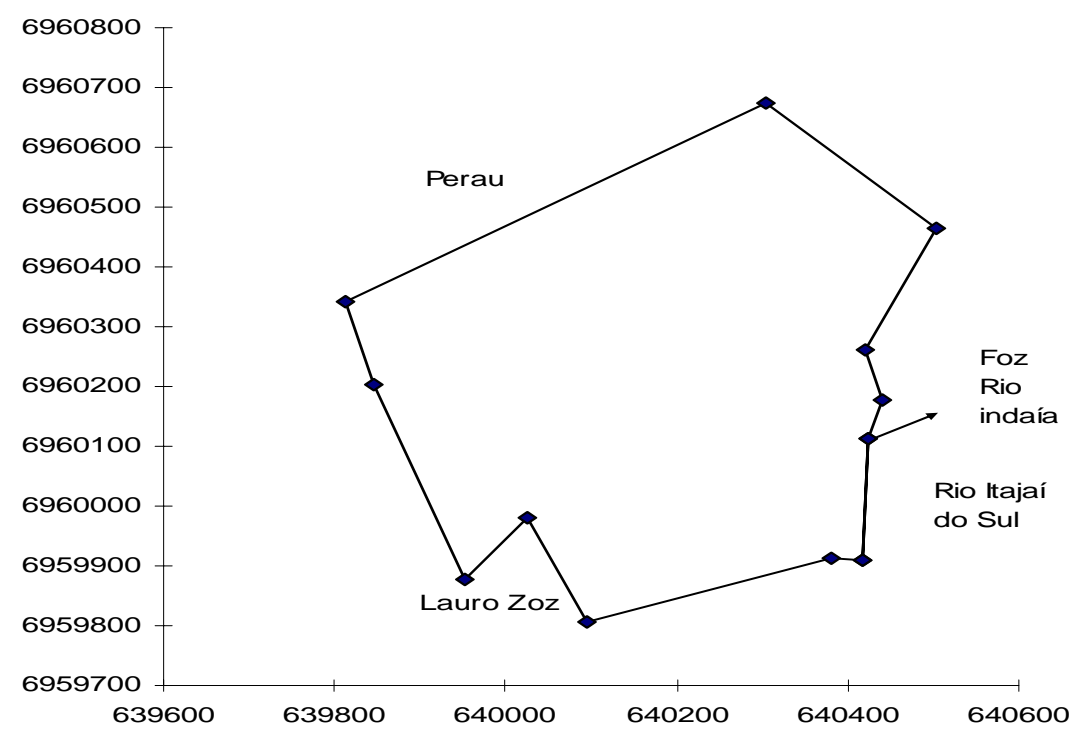

Figura 3 - Croqui da área 


\section{3 - Resultados e discussão}

De acordo com a Tabela 1 nos pontos de 01 a 06, a largura da mata ciliar existente não cumpre o que estabelece a Lei $\mathrm{n}^{0} 4771$ (Brasil, 1965), face a largura do rio ser de $70 \mathrm{~m}$, cuja faixa de mata ciliar deveria ser de 100 metros.

Tabela 1 - Largura da mata ciliar do Rio Itajaí do Sul inserida na área de estudo

\begin{tabular}{llll}
\hline PONTOS & LARGURA DO RIO & LARGURA DA MATA CILIAR & $\begin{array}{l}\text { Código Florestal } \\
n^{0} 4771 / 65\end{array}$ \\
\hline 01 & $>70$ metros & 50 metros & 100 metros \\
02 & $>70$ metros & 50 metros & 100 metros \\
03 & $>70$ metros & 45 metros & 100 metros \\
04 & $>70$ metros & 0 metros & 100 metros \\
05 & $>70$ metros & 20 metros & 100 metros \\
06 & $>70$ metros & 20 metros & 100 metros \\
\hline
\end{tabular}

Esta diferença na metragem pode ser melhor observada na Figura 4, onde a esquerda tem-se a largura do rio e a mata ciliar necessária, e a direita a metragem referente a mata ciliar existente. Na referida figura pode ser visualizado que há uma queda significativa na existência da mata ciliar.

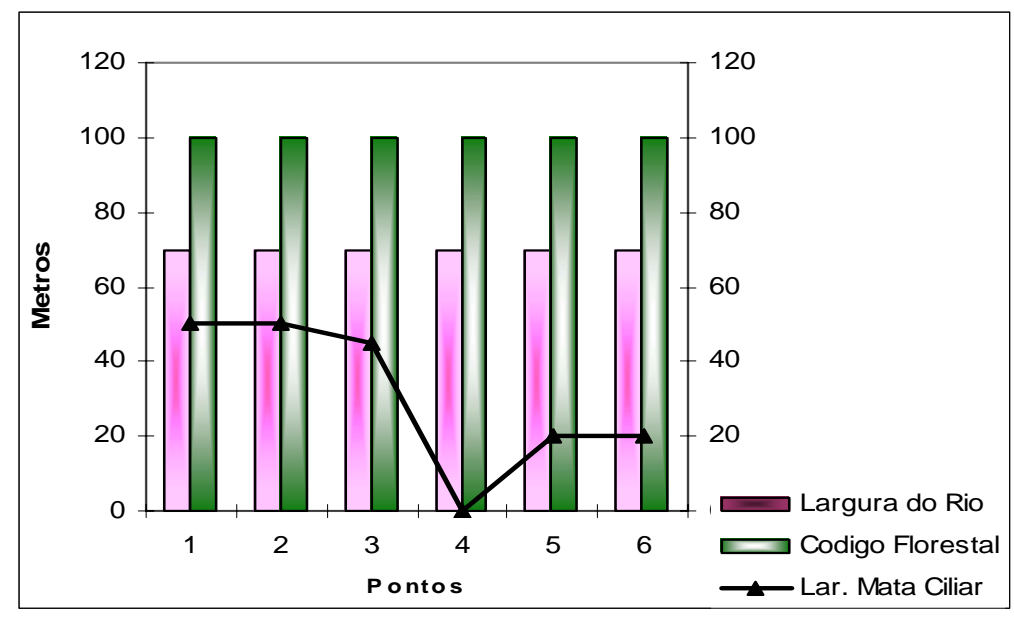

Figura 4 - Representação da largura da mata ciliar existente comparando a largura do rio Itajaí do Sul com a legislação ambiental brasileira (código Florestal Lei nº 4.771/65).

As características da área de preservação permanente do Rio Itajaí do Sul podem também ser vistas nas Figuras 5 a 8. 


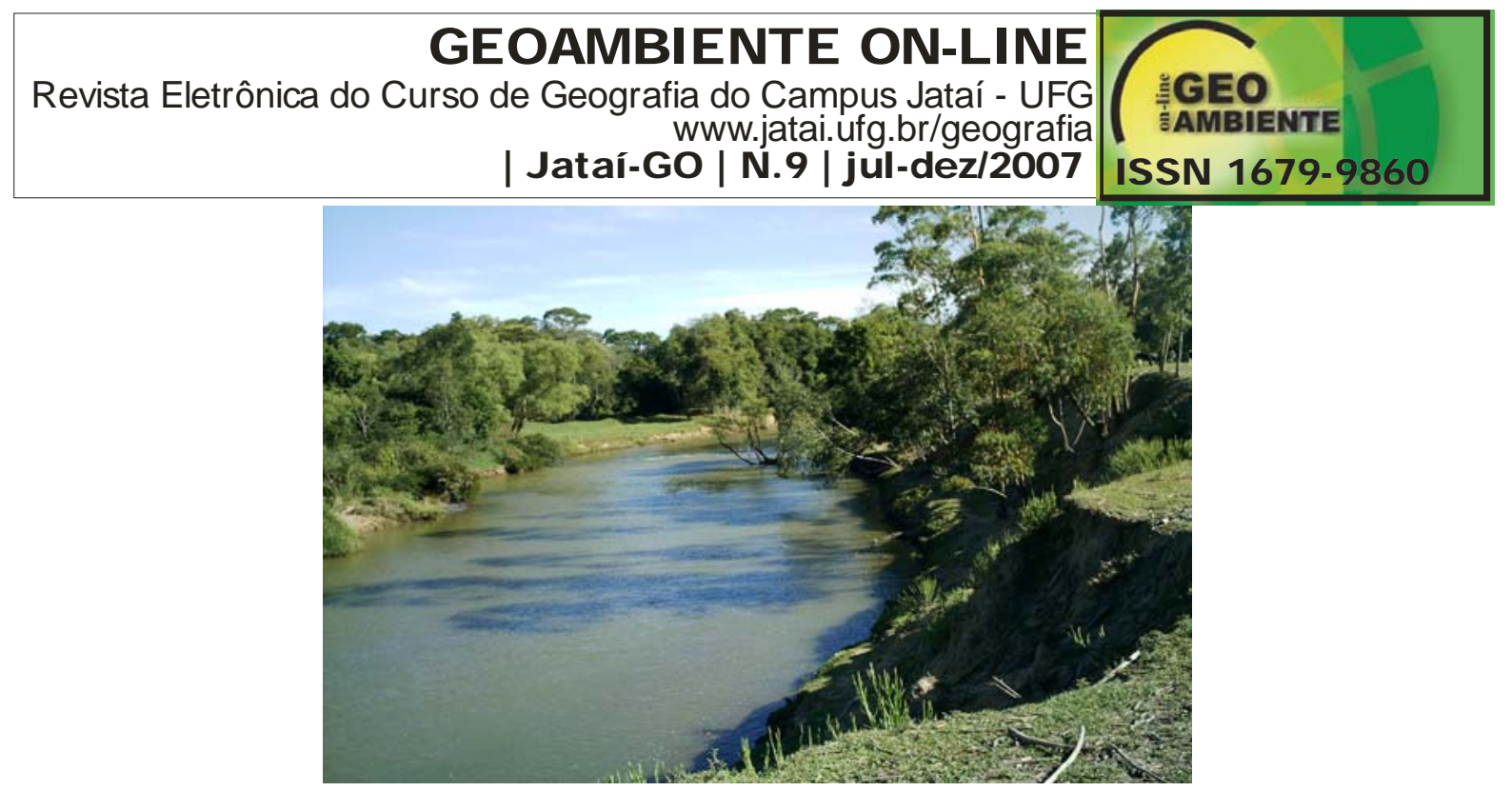

Figura 5 - Margem do Rio Itajaí do Sul na propriedade estudada

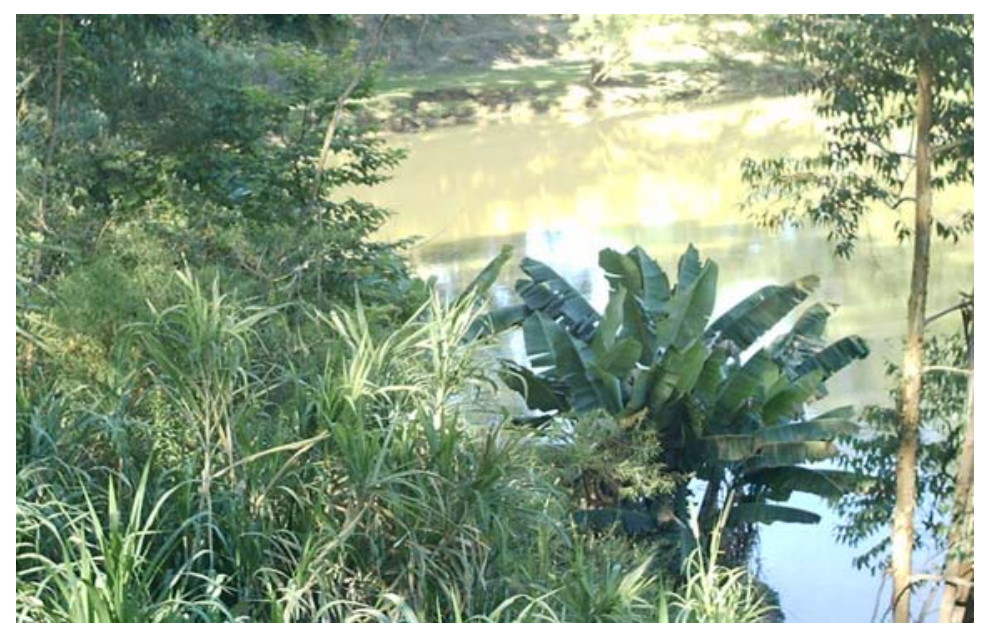

Figura 6 - Margem do Rio Itajaí do Sul na propriedade estudada

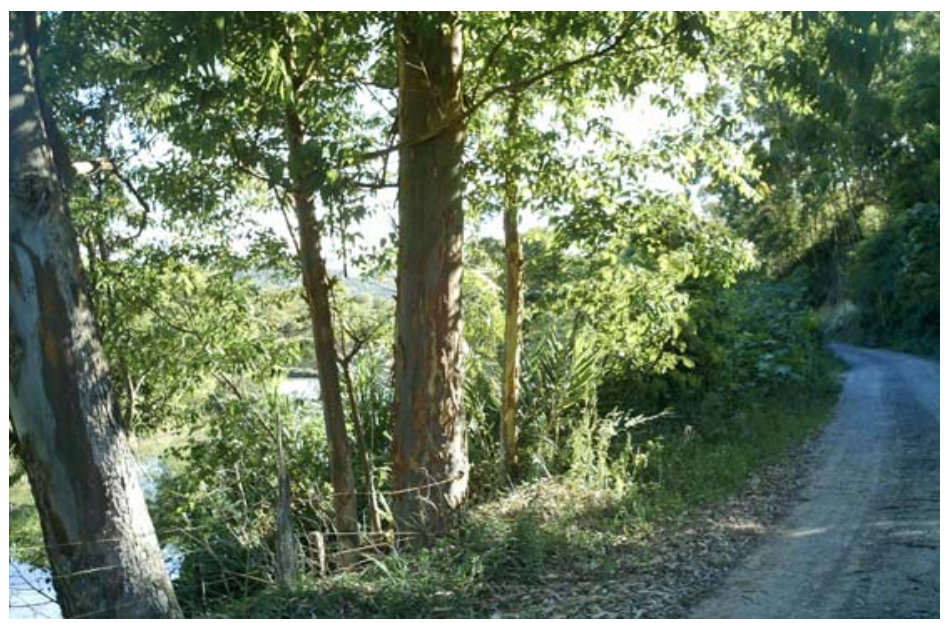

Figura 7 - Área de preservação permanente - Rio Itajaí do Sul. 


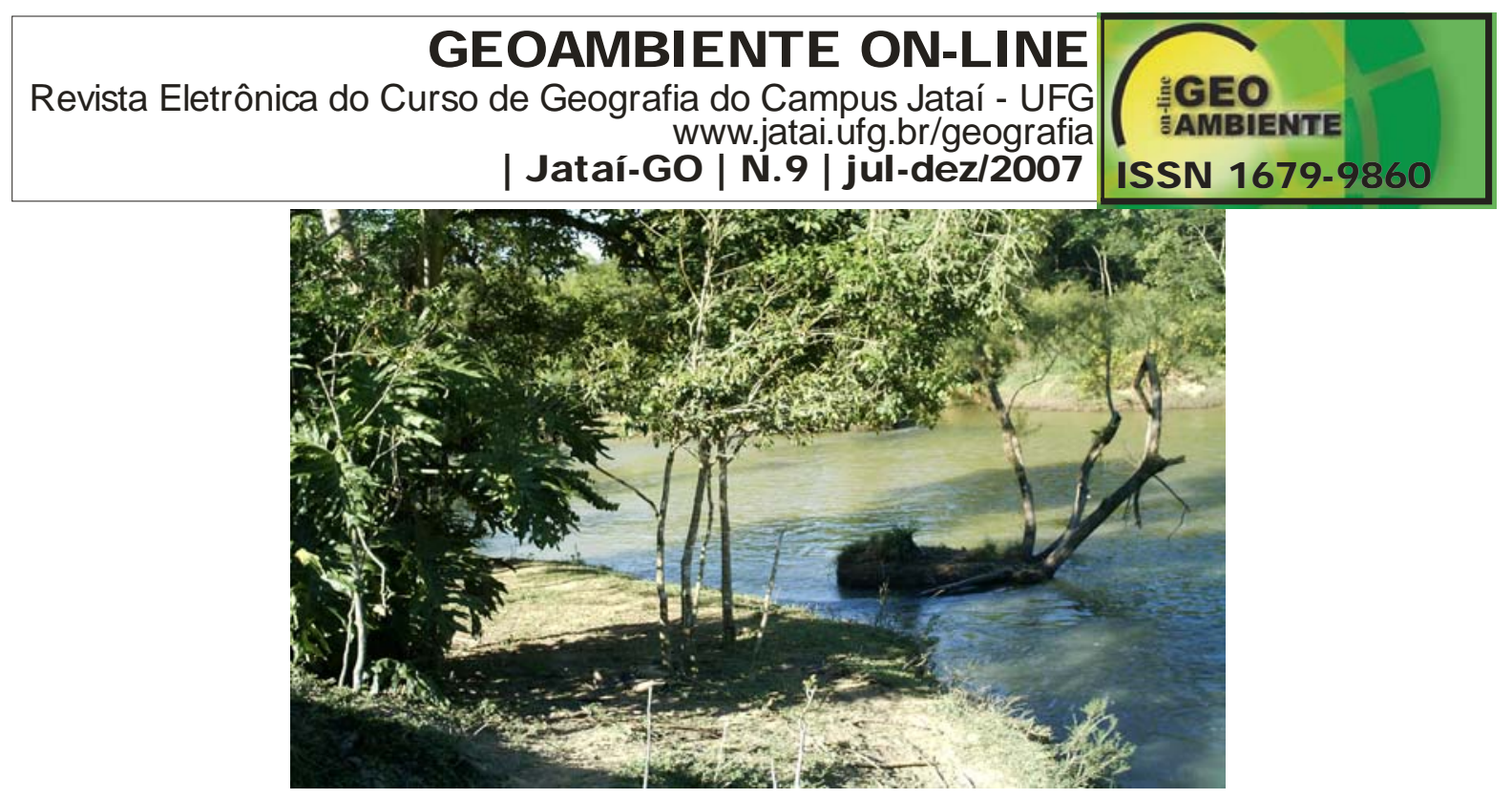

Figura 8 - Margem do Rio Itajaí do Sul próximo a foz do Rio Indaiá.

Com relação a área de preservação permanente do Rio Indaiá, a área de mata ciliar está ao redor de $10 \%$ do exigido por lei que são de 30 metros para rios de até 10 metros de largura (Brasil, 1965). Como o Rio Indaiá corta a propriedade, seriam necessários mata ciliar com 30 metros de largura em ambos os lados do rio.

Na Tabela 2 observa-se que a largura do Rio indaiá varia entre 2,5 a 4 metros. A largura da mata ciliar está entre 0 até 30 metros. As áreas de preservação permanente estão sendo ocupadas por pastagem e lavoura. A área necessária para a recomposição da mata ciliar de acordo com a legislação é de 14 hectares.

Tabela 2 - Medições da mata ciliar do Rio Indaiá

\begin{tabular}{llll}
\hline Pontos & $\begin{array}{l}\text { Largura } \\
\text { do rio } \\
\text { (metros) }\end{array}$ & $\begin{array}{l}\text { Largura da } \\
\text { mata ciliar } \\
\text { (metros) }\end{array}$ & $\begin{array}{l}\text { Código Florestal } \\
\text { Largura da mata } \\
\text { (metros) }\end{array}$ \\
\hline 01 & 4 & 4 & 30 \\
02 & 4 & 3 & 30 \\
03 & 3 & 1 & 30 \\
04 & 3,5 & 0 & 30 \\
05 & 3 & 2 & 30 \\
06 & 3 & 2,5 & 30 \\
07 & 2,8 & $* 1$ e 7 & 30 \\
08 & 2,9 & $* 2$ e 9 & 30 \\
09 & 2,8 & 1 & 30 \\
10 & 2,5 & $>30$ e *3 & 30 \\
\hline
\end{tabular}

Obs: * Em direção a montante referente a margem esquerda do rio.

Na Figura 10 encontra-se um comparativo entre a mata ciliar existente com a mata necessária de acordo com o Código Florestal (BRASIL, 1965). 


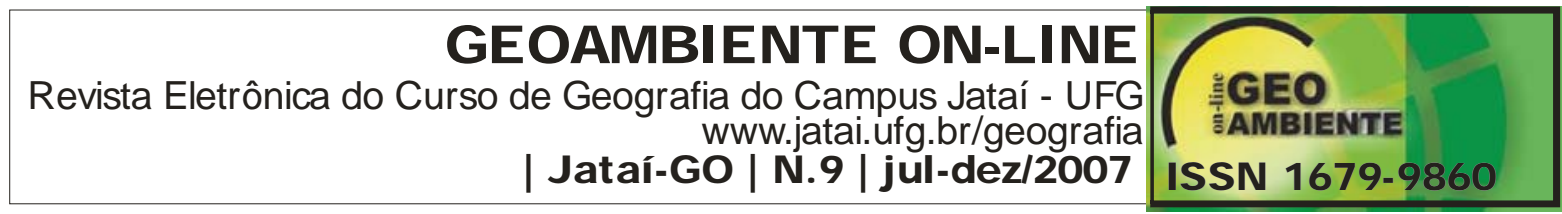

Em propriedades pequenas como no presente caso, a legislação ambiental é discutida pelos proprietários, principalmente em função de que a maioria das áreas que poderiam ser utilizadas para agricultura, estarem localizadas em locais com topografia plana, próximas aos cursos de água e que por força de Lei ambiental, devem ser utilizadas para preservação permanente. Nas figuras 11 a 14 observa-se as áreas de preservação permanente do Rio Indaiá.

O estado de Santa Catarina quando aplica a legislação ambiental, de certa forma tem dificuldades em cumpri-la, pois possui topografia acidentada, cujas melhores áreas para cultivo estão justamente próximo aos cursos d'água, assim como para a construção das cidades.

A legislação ambiental brasileira de 1965 estabeleceu de forma bastante generalizada à metragem da largura da vegetação em todo o país. Esta tem criado muitos conflitos, principalmente devido a pluralidade do território brasileiro, em função dos diferentes ecossistemas, cujo país possui dimensões latitudinais.

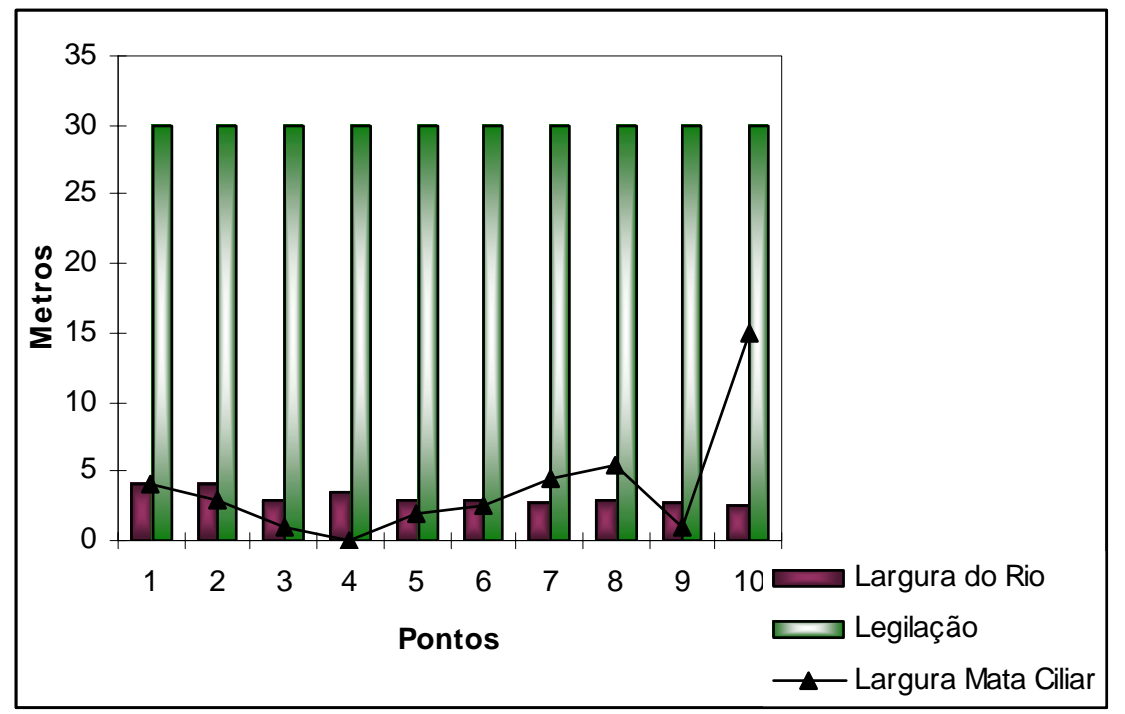

Figura 10 - Representação da largura da mata ciliar existente comparando a largura do rio Indaiá, relacionado com a legislação ambiental Brasileira, (Código Florestal Lei nº 4.771/65). 


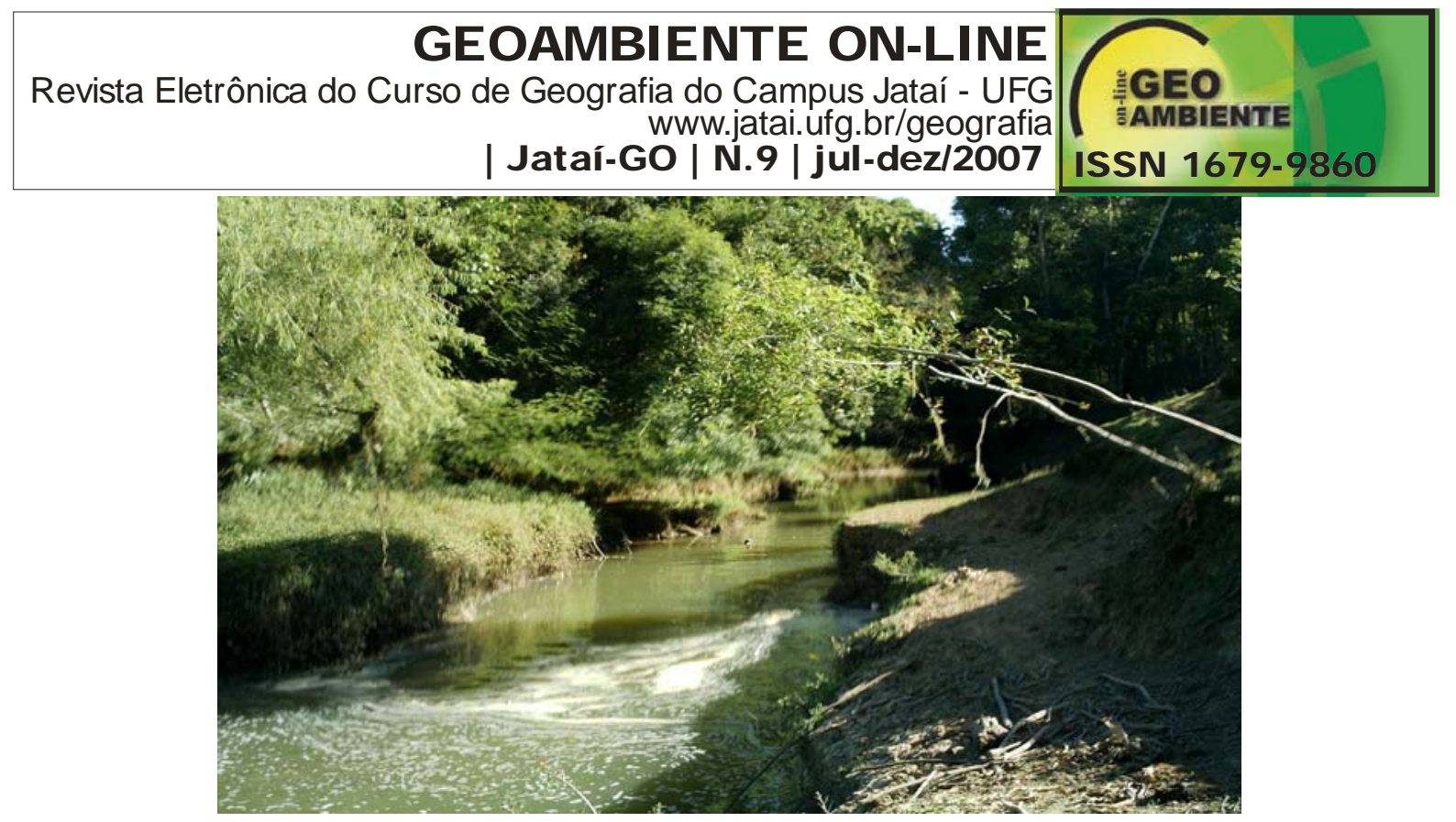

Figura 11 - Margens do rio Indaiá pouco acima da Foz.

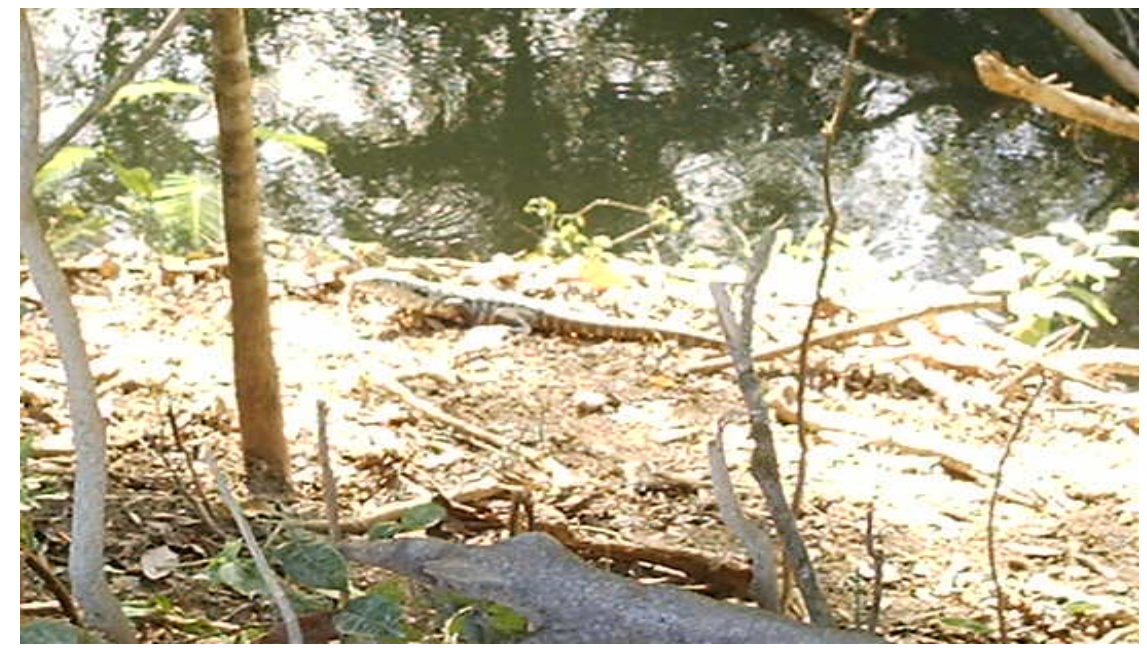

Figura 12 - Margem do rio Indaiá - indícios de fauna.

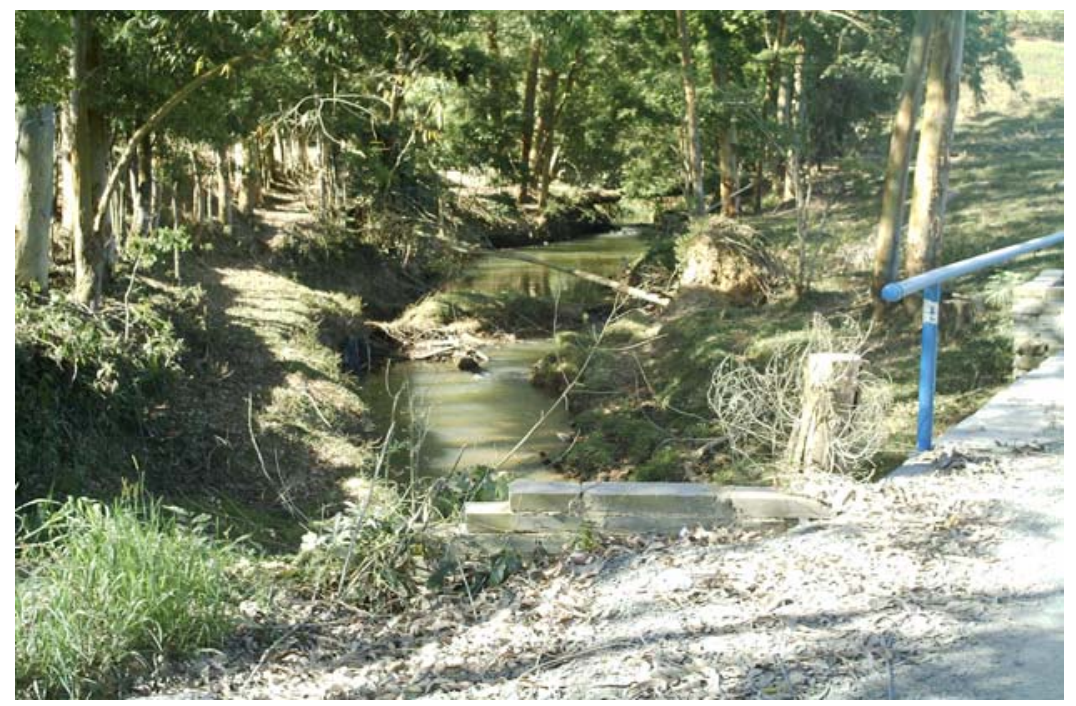

Figura 13 - Margens do Rio Indaiá - espécies exóticas 

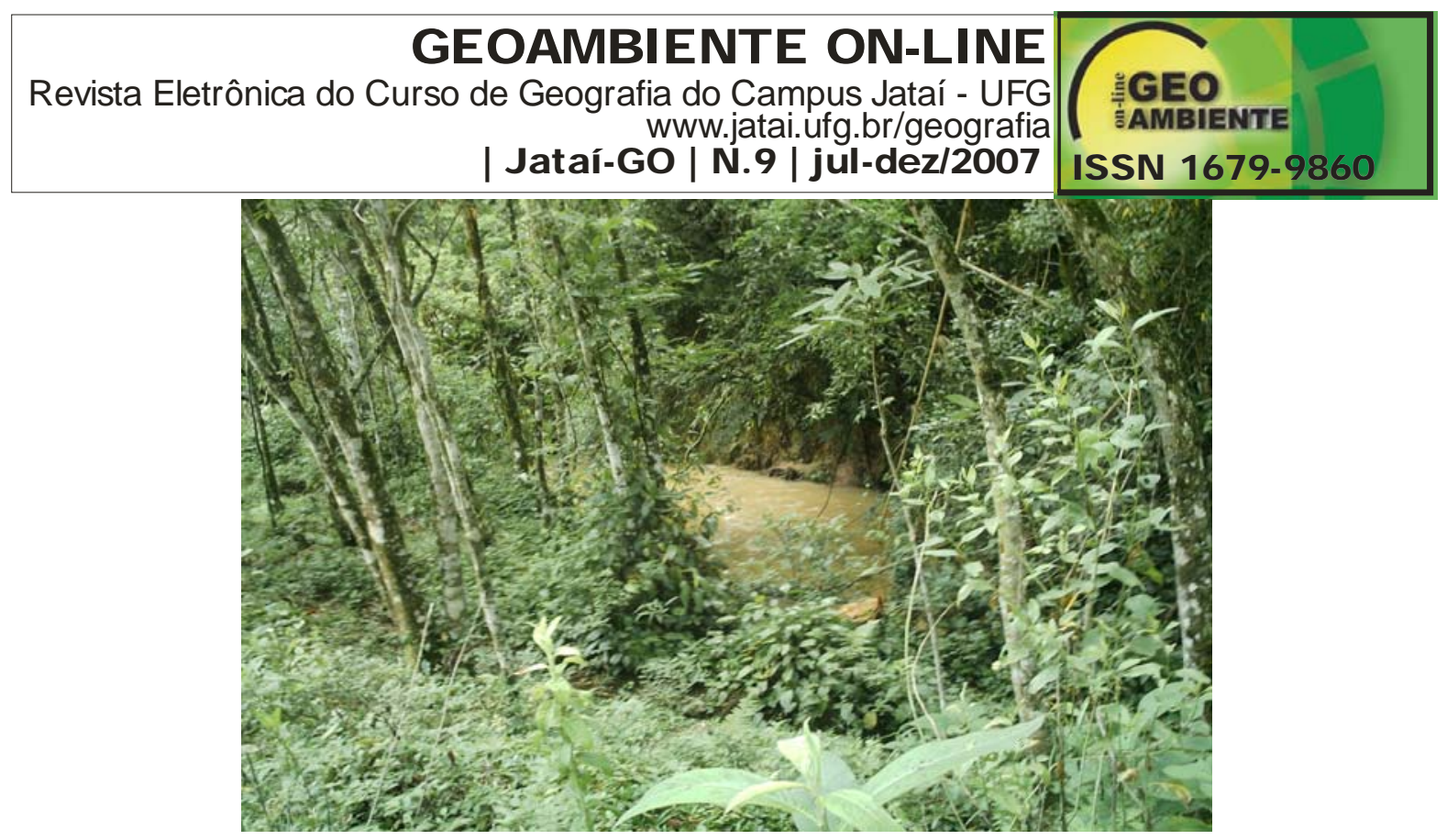

Figura 14 - Margem do Rio Indaiá - vegetação em recuperação.

\section{4 - Uso e ocupação do solo}

A área de estudos possui 23 ha utilizada com atividades agropecuárias e 9 ha com vegetação nativa. Na Figura 15 pode-se visualizar o relevo da área, na qual se observa faixas de mata ciliar margeando os rios e nascentes que não atendem a legislação ambiental. Mata ciliar, florestas ciliares ou florestas de galerias, incluem todos os tipos de vegetação arbórea encontrada perto dos recursos hídricos.

Estas foram assim denominadas por terem a mesma função dos cílios dos olhos, proteção. Elas agem como filtros, pois, receptam as águas das chuvas, diminuindo seu impacto sobre os solos. As florestas ciliares são formadas pelos mais diferentes tipos de vegetação como: árvores, arbustos, sub-arbustos e gramíneas. Assim, esta diversidade de plantas forma um emaranhado de raízes, que ajudam a manter a porosidade do solo, além de contribuir para a preservação das margens (BUTZKE, 2000; AB’SABER, 2001).

A mata ciliar do ponto de vista econômico é bastante conflitante: para os pecuaristas, ela é um obstáculo para o acesso do gado na água; para os silvicultores, estas áreas ribeirinhas representam sítios bastante produtivos, onde crescem árvores de alto valor comercial; em regiões de topografia acidentada, são as áreas apropriadas para a construção de estradas; e ainda para o abastecimento de água e energia, são as áreas apropriadas para inundação (BREIN, 1993).

LIMA \& ZAKIA (2001) afirmam que sob o ponto de vista hidrológico florestal, levando em conta a integridade das microbacias hidrográficas, as matas ciliares ocupam as 


\begin{tabular}{|c|c|}
\hline $\begin{array}{r}\text { GEOAMBIENTE ON-LINE } \\
\text { Revista Eletrônica do Curso de Geografia do Campus Jataí - UFG } \\
\text { | | ataí-GO | N.jatai.ufg.br/geografia } \\
\text { jul-dez/2007 }\end{array}$ & $\begin{array}{l}\text { YGEO } \\
\text { ISAMBIENTE } \\
\text { ISSN } 1679-9860\end{array}$ \\
\hline
\end{tabular}
geomorfológicos.

As zonas riparias (mata ciliar) são importantes corredores ecológicos, facilitam a movimentação da fauna ao longo das paisagens, assim como para dispersão vegetal. Além de espécies típicas de zonas ripárias, nestas áreas podem ocorrem espécies típicas de áreas de terra firme, sendo assim um banco de sementes para o processo de regeneração natural (GREGORY et al. 1992).

O uso do solo (Figuras 16, 17 e 18) é de forma diversificada com as seguintes atividades: Gado de leite, produção de cebola, milho como silagem e grãos, hortaliças, feijão, aves para consumos entre outras atividades domesticas. Em função da topografia variada, nas partes planas usam-se atividades agrícolas, e nas naquelas declivosas, utilizam-se para florestas.

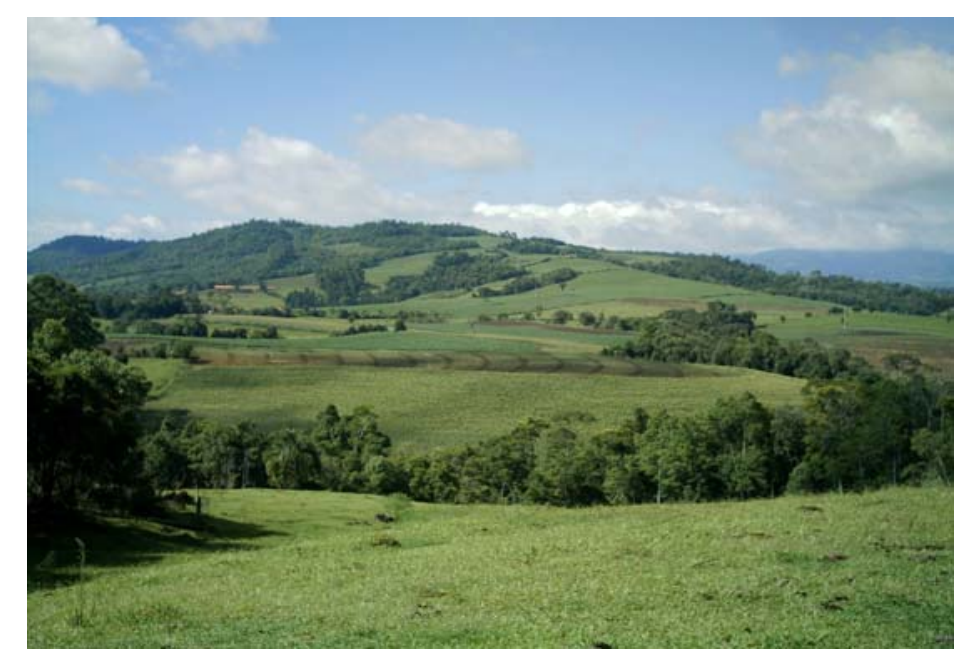

Figura 15 - Vista geral do uso e ocupação do solo. 


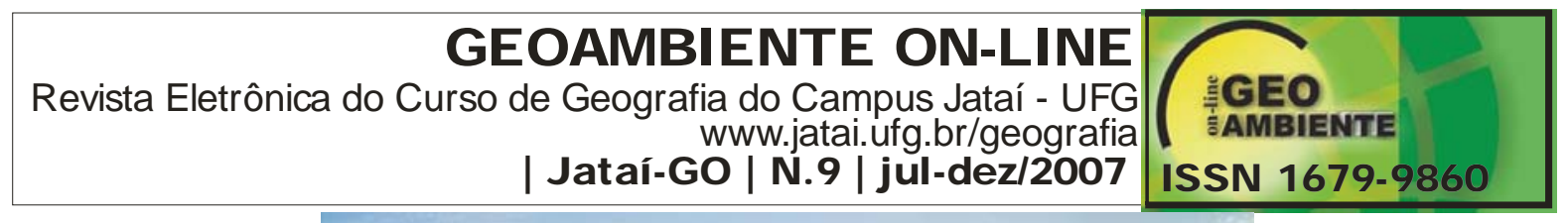

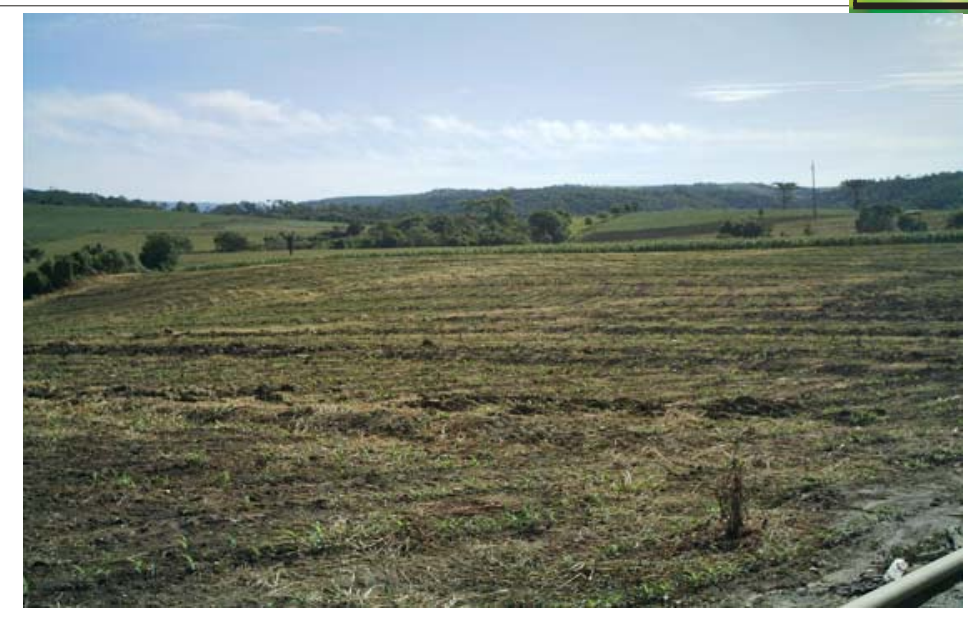

Figura 16 - Ocupação do solo com o plantio recente de milho, sobre a forma de plantio direto.

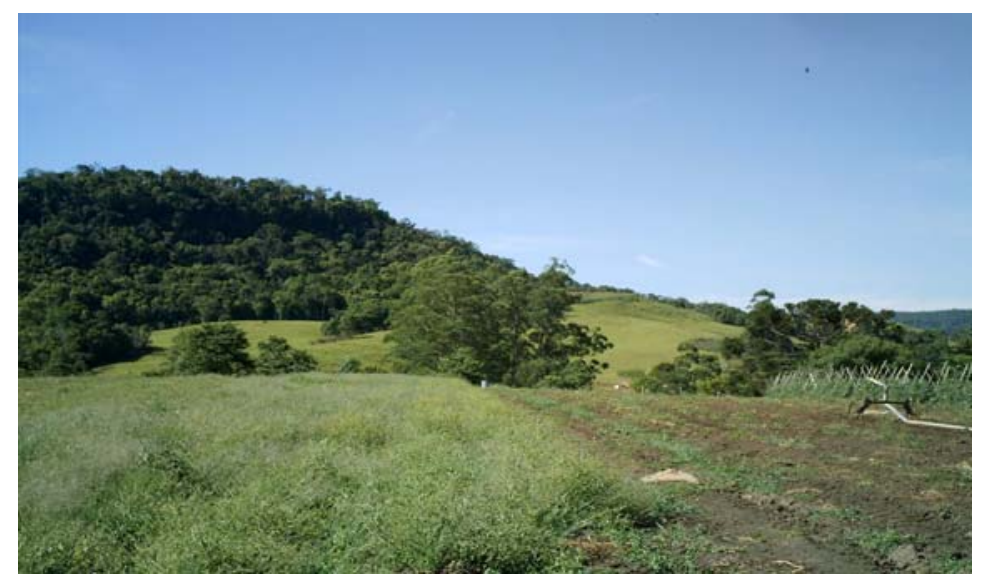

Figura 17 - Ocupação do solo da propriedade, ao fundo áreas de pastagens e área de preservação permanente.

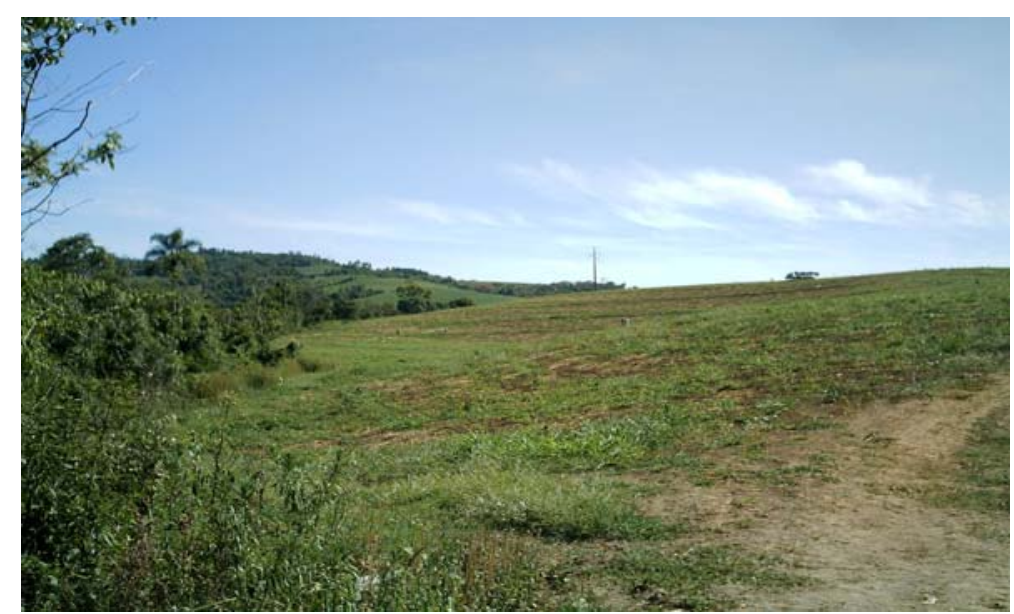

Figura 18 - Área utilizada para o cultivo da cebola.

Como o estado de Santa Catarina é predominado por pequenas propriedades com áreas nas faixas de 15 a 20 hectares. Caso fosse aplicada a legislação ambiental na área de estudos, 


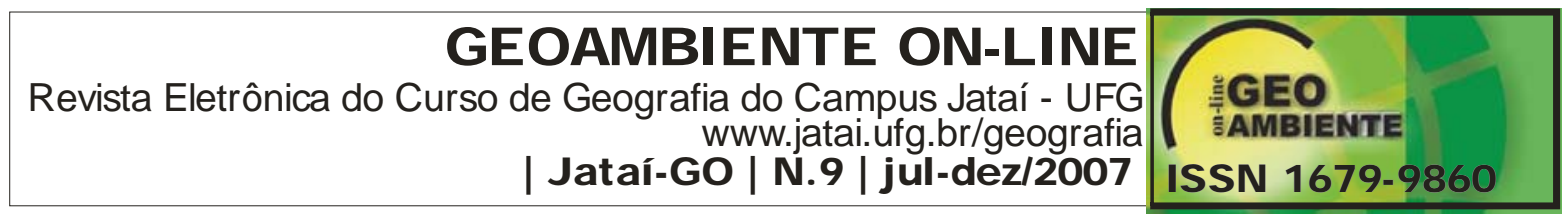

é possível que a mesma se tornasse economicamente inviável, porque se perderia áreas ocupadas com pastagens e agricultura.

As normas da Constituição Federal Brasileira de 1988, em suas normas relativas ao meio ambiente, de forma geral, visa o desenvolvimento sustentável. Delimita alguns parâmetros, e principalmente a função do poder público diante dos recursos naturais. No capítulo III, sobre a política agrícola, fundiária e da reforma agrária, artigo 186, a função social é cumprida quando a propriedade rural atende, simultaneamente, segundo critérios e graus de exigência estabelecidos em lei aos requisitos de: aproveitamento racional e adequando; utilização adequada dos recursos naturais disponíveis e preservação do meio ambiente; observância das disposições que regulam as relações de trabalho; e a exploração que favoreça o bem estar dos proprietários e dos trabalhadores (PIRES \& PETERES, 2001).

Assim, através da proposição de princípios, de diretrizes e de mecanismos de estruturação, controle e tomada de decisões gerenciais (sistemas de acompanhamentos), promovem o uso, a proteção, a conservação e o monitoramento de recursos naturais e sócioeconômicos do espaço rural, tendo sempre em foco as vertentes ecológicas, econômicas e sociais nessas atividades.

Entretanto, as diferentes alternativas para implantar essa forma de se buscar sustentabilidade (definição de políticas regionais ou estaduais, política nacional de meio ambiente e planos “verdes”), impediam que seus benefícios fossem medidos com a acuidade necessária, com reprodutibilidade e, principalmente, comparáveis a outros inúmeros cenários propostos internacionalmente (SILVA, 1997).

Nas Figuras 19 e 20 tem-se um comparativo do uso atual com o uso adequado as normas ambientais. Observa-se que a área em estudo terá boa parte da área de pastagem e da área agrícola reflorestada principalmente devido a presença de dois rios e algumas nascentes. A área que deveria ser reflorestada é de aproximadamente 10 ha, pois, além do rio, a propriedade possui diversas nascentes que segundo o Código Florestal, necessitam de 50 metros de circunferência de mata nativa, além do que, os córregos de até 10 metros de largura devem ter 30 metros de vegetação em ambos os lados. 


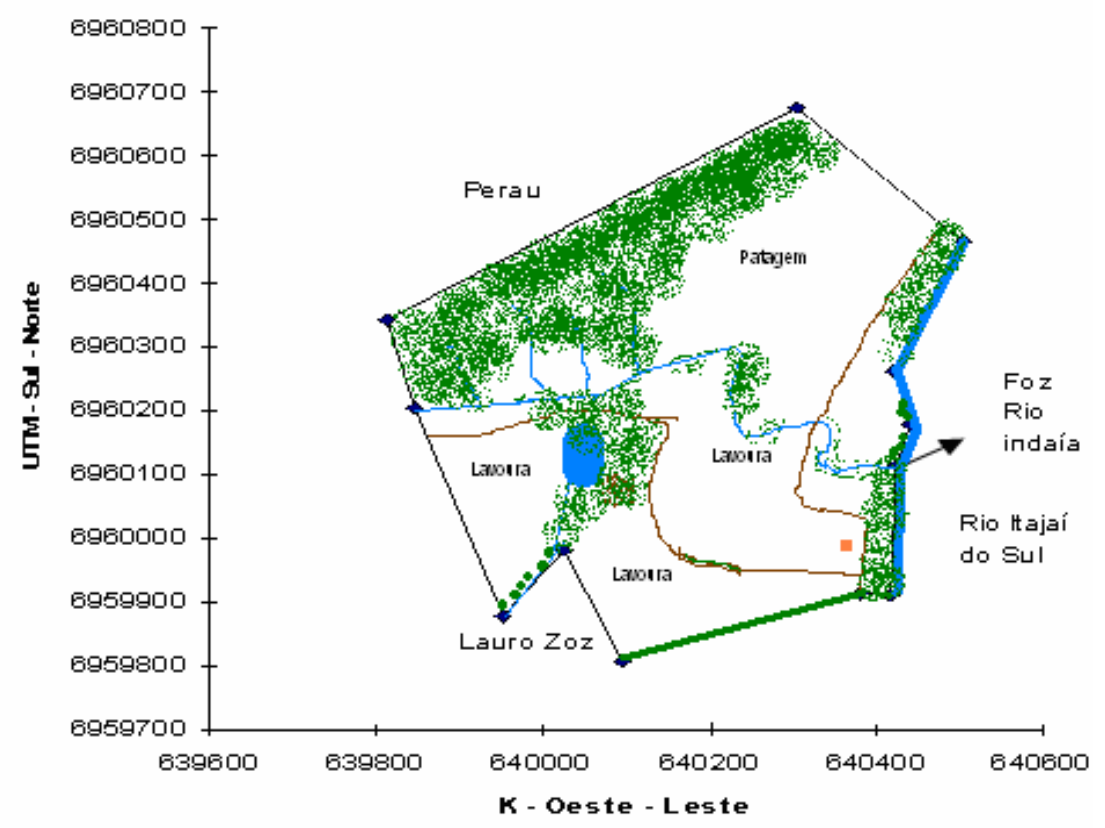

Figura 19 - Croqui georreferenciado do uso e ocupação do solo atual: em destaque rios (azul), estradas (marron), vegetação (verde) e sede (vermelho).

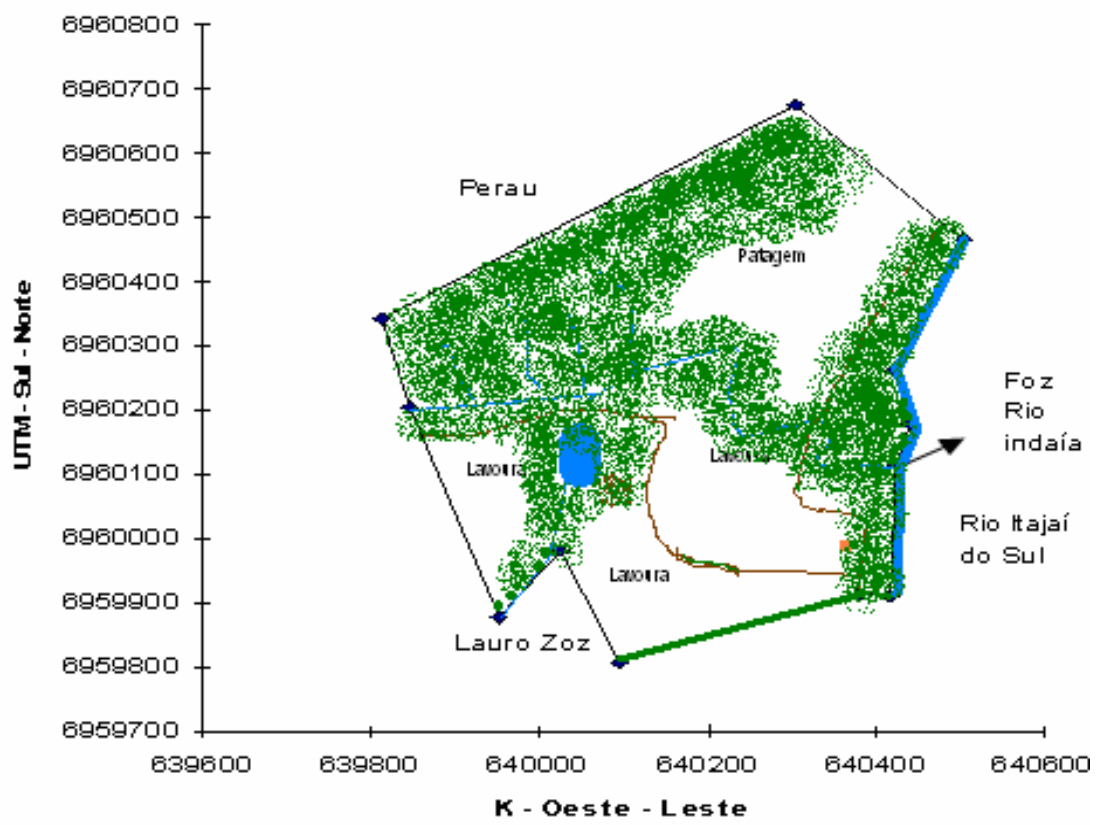

Figura 20 - Croqui georreferenciado do uso e ocupação do solo após o plano de gestão ambiental: em destaque rios (azul), estradas (marron), vegetação (verde) e sede (vermelho).

\section{5 - Conclusões}


- De acordo com a legislação ambiental seriam necessários acrescentar em torno de 10 hectares de reflorestamento com espécies nativas, principalmente nas áreas ocupadas com pastagem.

- Se a propriedade fosse enquadrada por um Termo de Ajustamento de Conduta de acordo com a legislação ambiental, possivelmente se tornaria economicamente inviável.

\section{6 - Referências Bibliográficas}

AB'SABER, A. N. O suporte geológico das florestas Beiradeiras (ciliares). Matas ciliares, conservação e recuperação. 2 ed. FAPESP. São Paulo. 319p. 2001.

ALMEIDA, J. R; MELLO, C. S \& CAVALCANTTI, Y; Gestão Ambiental:Planejamento, Avaliação, implantação, operação e verificação. Rio de Janeiro. Ed Thex. 2000.

BRASIL. Lei $\mathrm{n}^{0} 4.771$ de 15 de Setembro de 1965. Institui o novo código florestal. Disponível em: <www.planalto.gov.br/ccivil_03/LEIS/L4771.htm>. Acesso em 10 de novembro de 2006.

BREIN, L. J. Riparian Zone, Stream, and Floodplain Issues: A Review. Journal of Hydrology, 150:277-299. 1993

BUTZKE, I. C. Mata ciliar - proteção da água: campanha de cidadania pelas água no Vale do Itajaí. FURB. 39p.2000.

EHRLICH, P. R. A perda da Diversidade - Causas e Conseqüências - Biodiversidade - Org. Wilson E. O. Ed Nova Fronteira, 27-35p. 2000.

GREGORY, S.V; SWANSON, F. J.; MCKEE, W. A \& CUMMINS, K. W. An ecosystem Perspective of riparian zones. BioSciense, 41 (8): 540-511, 1992.

LEGEET, J. O aquecimento global. O relatório do Greenpeace. Rio de Janeiro, Ed. Fundação Getulio Vargas. 512p. 1992.

LIMA, W. P \& ZAKIA, M.J.B. Hidrologia de matas ciliares. Matas ciliares, conservação e recuperação. 2 ed. FAPESP. São Paulo. 319p. 2001.

PIRES, P. T de L; PETERS, E.L. Legislação ambiental federal. Juruá. Curitiba, 2C - - - -

SILVA, A. DE S.; Racionalização do uso de agrotóxicos em frutas irrigadas

para adequação dos padrões de qualidade ISSO 14.000: Dipólo agroindustrial Petrolina(PE)/Juazeiro (BA). 1997. 